of citrate and $0.30 \mathrm{mg} / \mathrm{100} \mathrm{ml}$ of malate. The level of citrate in serum was thus slightly above the upper borderline of normal values; the levels of malate were normal.

Department of Medical Chemistry, J. Fv. Purkynĕ University, Brno EMAN ZeLnf́čeK Research Institute of Pediatrics, Brno Antonín Mrskoš Department of Pediatrics, Hospital, Znojmo (Czechoslovakia) Ferdinand Krystík

I. L. OEI, Clin. Chim, Acta, 7 (1962) I93.

2 E. Zelní̌ek, Clin. Chim. Acta, 7 (r962) 592.

3 R. R. Howell, D. M. Ashton and J. B. Wyngaarden, J. Clin. Invest., 39 (1960) 997.

4 H. E. Holling, Ann. Internal Med., 58 (1963) 654.

5 R. H. Ettinger, L. R. Goldbaum and L. H. Smith, J. Biol. Chem., I99 (I952) 531.

- H. J. Hohorst, F. H. Kreutz and Th. Bücher, Biochem. Z., 332 (1959) 18.

Received February 9, 1964

Clin. Chim. Acta, $9(1964) 587-589$

\title{
Quantitative determination of ammonia in cattle blood for routine analysis
}

In I939, CONWAY AND COOKE ${ }^{1,2}$ published a method for the quantitative determination of ammonia in human blood. According to the authors, a disadvantage of this method is that the determination has to be carried out as soon as possible after blood sampling, as the concentration of ammonia starts to rise immediately.

In our investigations on the pathogenesis of hypomagnesaemic tetany in cows it was not possible to perform the determination immediately after venipuncture, as we had to sample blood at a great distance from the laboratory.

The method described by NATHAN AND RODKEY ${ }^{3}$ proved to be more suitable for our purposes, provided it was modified and completed in some respects. The following modifications have been made.

I. The blood sample is taken from the jugular or mammary vein, trapped in a glass-stoppered measuring cylinder (capacity $35 \mathrm{ml}$ ) containing some drops of a solution of $5 \%$ heparin. The cylinders are rapidly filled to the top and cooled in a Dewar flask containing melting ice. We had to introduce this modification as it was impracticable to deproteinize the blood at the farm. It has been found repeatedly that cattle blood could be stored for more than I $h$ without any increase of the ammonia concentration. This confirms the findings of MERCHANT et al. ${ }^{4}$.

2. Contrary to the findings of NATHAN AND RODKEY ${ }^{3}$ we found that the bloodtrichloroacetic acid mixture must be centrifuged in a refrigerated centrifuge. Neglect of this precaution results in a rise of the ammonia concentration.

Furthermore, we have verified how long the supernatant could be stored before a rise of the ammonia concentration set in. We found that the ammonia concentration did not rise during at least $24 \mathrm{~h}$, provided the supernatant contained no particles of denatured protein and was stored in frozen condition at $-10^{\circ}$. This matter had to be investigated, as it was not always possible to perform the determination immediately after deproteinizing. Our results agree very well with the results obtained by BROMBERG et al..$^{5}$. They did not observe a rise of the ammonia concentration even after a storage time of 3 weeks at $-10^{\circ}$. 
The influence of the addition of a $20 \%$ solution of trichloroacetic acid to an equal quantity of cattle blood on the possible release of ammonia by this acid from nitrogen-containing substances of blood has been extensively investigated. For this purpose we mixed blood (immediately after drawing) with an equal amount of the acid and stored the mixture in melting ice. At regular intervals, a sample was centrifuged and the quantity of ammonia in the supernatant determined. From a number of experiments it became clear that between 5 and 60 min after sampling, there was no rise in the concentration of ammonia in the supernatant fluid.

To check the reproducibility of the described method, recovery experiments were carried out. To samples from the same pool of cattle blood, different quantities of ammonium sulphate (0.10-I.00 $\mu \mathrm{g}$ per $\mathrm{ml}$ of blood) in an equal quantity of water were added. The mean recovery was $97.9 \%$ (S.D. I2 $\%, n=20$ ). After omitting one low value $(60 \%)$, the mean recovery was $99.9 \%$ (S.D. $9 \%, n=\mathrm{Ig})$. Furthermore, we added different amounts of ammonium sulphate (I.00-I.75 $\mu \mathrm{g}$ per $\mathrm{ml}$ ) to the solution of trichloroacetic acid used for deproteinizing the blood samples. In this case, the mean recovery was Ior. $4 \%$ (S.D. $5.5 \%, n=8$ ).

As a means to prevent coagulation of the blood, we used a $5 \%$ solution of heparin. This substance prevents the action of adenylic acid deaminase as found by DiMOND ${ }^{8}$ and confirmed by DE GROOTE AND VANDENRROUCKE?

The author is greatly indebted to Prof. Dr. L. SEEkLEs for his stimulating interest and to Mr. H. K. Nobels for skilled assistance.

Laboratory of Veterinary Biochemistry,

H. J. HENDRIKS

State University of Utrecht

(The Netherlands)

1 E. J. Conway, Microdiffusion and Volumetric Error, Crosby Lockwood and Son, London, 1947.

2 E. J. CONWAY AND R. COOKE, Biochem. J., 33 (1939) 457.

3 D. G. Nathan and F. Z. Rodkey, J. Lab. Clin. Med., 49 (1957) 779.

* A. C. Merchant, R. Goldberger and H. G. Baker, J. Lab. Clin. Med., 55 (1960) 790.

5 P. A. Bromberg, E. D. Robin and C. E. Foukner, J. Clin. Invest., 39 (1960) 332.

- F. G. Dimonn, J. Lab. Clin. Med.. 46 (r955) 807.

"J. de Groote and J. Vandenbroucke, Am. J. Digest. Diseases, 3 (r958) 502.

Received December 24th, r963

Revised manuscript received March 2nd, I964

Clin. Chim. Acta, $9(1964) 589-590$

\section{Starch substrate with improved stability for the clinical determination of amylase activity}

A significant methodologic advance was achieved by CARAWAY ${ }^{1}$ in providing a practical micro procedure for determination of amylase in various body fluids. However, under the exigent conditions of clinical laboratory usage, we were not able to guarantee a stability of greater than $7-8$ months for his starch substrate. CARAWAY ${ }^{1}$ used sodium benzoate as a preservative for his starch substrate which was buffered to $\mathrm{pH} 7.0$ with phosphate. RICE ${ }^{2}$, pursuing a similar methodologic approach, used 